\title{
Criterios jurisprudenciales en el derecho de familia chileno para fundamentar la autorización para salir del país de niños, niñas y adolescentes y su relación con el principio del interés superior de éstos y con la familia extendida*
}

\author{
1 Constanza Astudillo Meza**
}

RESUMEN. El presente trabajo analiza sentencias dictadas por la Corte Suprema y por las cortes de apelaciones de Chile que se pronuncian acerca de la autorización para que niños, niñas y adolescentes salgan del país. Esta materia se encuentra regulada en la ley 16.618 y exige para conceder el referido permiso que la salida reporte un beneficio a los niños, niñas y adolescentes. En el presente trabajo analizaremos dicho beneficio a partir del interés superior del niño, considerando la relevancia de la familia extensa.

Palabras Clave: autorización para salir del país, interés superior del niño, niña y adolescente, beneficio, familia extendida.

* Fecha de recepción: 28 de febrero de 2020. Fecha de aceptación: 27 de abril de 2020.

Para citar el artículo: Astudillo Meza, C., "Criterios jurisprudenciales en el derecho de familia chileno para fundamentar la autorización para salir del país de niños, niñas y adolescentes y su relación con el principio del interés superior de éstos y con la familia extendida”, Revista de Derecho Privado, n. ${ }^{\circ}$ 39, julio-diciembre 2020, 397-407, Dor: https://doi.org/10.18601/01234366.n39.16.

** Universidad Santo Tomás, Antofagasta, Chile; profesora de Derecho civil. Estudiante del Programa de Doctorado en Derecho, Universidad Católica Argentina (UCA), Buenos Aires, Argentina. Magíster en Derecho, Universidad Católica del Norte, Antofagasta, Chile. Contacto: castudillom@santotomas. cl. Orcid: 0000-0001-9796-3492. 


\title{
Case Law Criteria in the Chilean family Law for Providing Authorization to Leave the Country for Children and Adolescents and its relationship with the Principle of the Best Interest of the Child and its Extended Family
}

\begin{abstract}
I analyze some Chilean Supreme Court and Courts of Appeal decisions regarding the authorization for children and adolescents to leave the country. This is regulated by Act 16.1618 which requires, as to grant the authorization, for the departure to prove beneficial for the children and adolescents. Here I analyze this benefit based on the best interest of the child and its extended family.
\end{abstract}

KEYWORDS: authorization to leave the country, principle of the best interest of the child and adolescents, benefits, extended family.

Sumario: Introducción. I. El interés superior del niño y la ley n. ${ }^{\circ}$ 16.618. II. Relevancia de los vínculos de familia. Conclusiones. Referencias.

\section{Introducción}

En el presente trabajo analizaremos los criterios de los tribunales superiores de justicia chilenos, esto es, Corte Suprema y cortes de apelaciones, relativos a la autorización para que un niño, niña o adolescente salga de Chile, materia regulada en el artículo 49 de la Ley n. ${ }^{\circ} 16.618^{[1]}$. Dicha norma, como regla general, requiere de la autorización notarial del padre o madre que no acompaña al niño, niña o adolescente, por lo tanto, "no es necesario este permiso si el menor sale en compañía de la persona o personas que deben prestarlo"2. Frente a la negativa de éste o ésta exige el mencionado precepto legal la autorización judicial otorgada por el juez de familia del domicilio del niño, niña o adolescente. Así, el inciso $60^{\circ}$ de la señalada legislación indica que "El juez, para autorizar la salida del menor en estos casos, tomará en consideración el beneficio que le pudiere reportar y señalará el tiempo por el que concede la autorización".

Resulta pertinente indicar que la mayoría de las sentencias que se expondrán en esta investigación resuelven recursos de casación en el fondo. Este medio de impugnación, en el derecho procesal chileno, consiste en "aquel acto jurídico procesal de parte agraviada con la dictación de determinadas resoluciones judiciales, por medio de la cual se solicita a la Corte Suprema que invalide dichas sentencias y dicte otra en su reemplazo"3. A mayor detalle, el recurso tiene una causal genérica: la infracción

1 Publicada en el Diario Oficial de fecha 8 de marzo de 1967, disponible en [www.leychile.cl/Nave gar?idNorma=28581].

2 Ramos Pazos, R. Derecho de Familia, t. II, 7. ed., Santiago, Editorial Jurídica de Chile, 2017, 466.

3 Orellana Torres, F., Manual de Derecho Procesal, 3. a ed., Santiago, Librotecnia, 2010, 161. 
de ley que influye sustancialmente en lo dispositivo del fallo. En los casos objeto del presente trabajo, dicha infracción implica la vulneración del principio de interés superior del niño ${ }^{4}$, insistimos, siempre que ésta influya sustancialmente en lo dispositivo del fallo. Súmese a lo anterior que el común denominador de las sentencias que estudiaremos está dado por su relación con la familia extensa.

\section{El interés superior del niño y la ley n. ${ }^{\circ} 16.618$}

En la introducción de este trabajo indicamos que la autorización para que niños, niñas o adolescentes salgan del país se encuentra disciplinada en la Ley n. ${ }^{\circ} 16.618$. Es procedente dejar constancia de que dicha legislación, a lo menos en términos expresos, no "prevé la posibilidad de una autorización de salida definitiva al extranjero, ya que la norma dice relación con una salida temporal, al imponerle al juez la exigencia de fijar un plazo para el retorno" 5 . Por lo dicho, se ha generado, siguiendo a Monte$\operatorname{cinos}^{6}$, una laguna legal, pues "la autorización definitiva al extranjero de un niño no está regulada en nuestra legislación, teniendo el interés superior del niño una función integradora. Por tanto, al no existir norma que regule explícitamente la salida del niño, niña o adolescente del país resulta fundamental la aplicación del principio de interés superior del niño ${ }^{7}$ desde su prisma de principio de interpretación" 8 .

En este sentido, el nombrado principio debe orientar las decisiones del juez de familia en Chile, en virtud de lo establecido en el artículo 16 de la ley que crea los tribunales de familia, ley n. ${ }^{\circ}$ 19.968. Sin embargo, debemos tener presente que

4 Es habitual que los recurrentes para efectos de invalidar decisiones de los tribunales de familia recurran al principio del interés superior del niño, pues la práctica judicial ha ido demostrando que la ley no es la única fuente a la que acuden los “jueces para resolver un conflicto”. Véase RoMERo SEGUEL, A., Aguirrezábal Grünstein, M. y Baraona González, J., "Revisión crítica de la causal fundante del recurso de casación en el fondo en materia civil", Ius et Praxis, vol. 14, n. 1, 2008, 225-259.

5 Montecinos Tota, A., "Interés superior del niño como fundamento de la autorización de su salida definitiva al extranjero", en Domínguez Hidalgo, C. (coord.), Estudios de Derecho de Familia III. Terceras Jornadas Nacionales. Facultad de Derecho. Pontificia Universidad Católica de Chile, Santiago, Thomson Reuters, 2018, 569-589.

6 Idem.

7 Este principio alude a asegurar al NNA el ejercicio y protección de sus derechos fundamentales y a posibilitar la mayor suma de ventajas, en todos los aspectos de su vida, en perspectiva de su autonomía y orientado a asegurar el libre desarrollo de su personalidad; concepto, en todo caso, cuyos contornos deben delimitarse en concreto, en cada caso. En CORTE SUPREMA, 9 de octubre de 2012, Rol n. ${ }^{\circ}$ 2.161-2011, considerando 11..

8 El interés superior del niño se perfila como una noción que excede los contornos de las normas jurídicas clásicas, se trata de un concepto extenso que se estructura de manera compleja, abarcando tres perfiles, a saber: como derecho, como principio y como norma procesal (así lo plantea la Observación General n. ${ }^{\circ} 14$ del Comité de los Derechos del Niño de la Naciones Unidas). Esto significa que se le reconocen tres dimensiones prioritarias: en primer lugar, una de índole sustantiva; en segundo término, como un principio jurídico interpretativo fundamental; y, finalmente, es una fórmula procesal que obliga a estimar las posibles repercusiones de cada decisión, antes de ser adoptada. En CoRTE Suprema de Chile, 18 de octubre de 2016, Rol n. 35.161-2016, considerando 7. . . 
el contenido del mencionado principio debe ser determinado teniendo en vista las particularidades de la litis de que se trate. De esta manera, como lo ha planteado Rodríguez, estamos en presencia de "un concepto que depende demasiado de las coordenadas personales y circunstancias del caso; y, además, es cambiante, evoluciona con el paso del tiempo" ". En consecuencia, el principio "le recuerda al juez o a la autoridad de que se trate que [...] no construye soluciones jurídicas desde la nada, sino en estricta sujeción, no sólo en la forma también en el contenido, a los derechos de los niños sancionados legalmente" 10 .

Observaremos en las sentencias analizadas que la fundamentación del principio del interés superior del niño será el elemento clave para conceder o rechazar la autorización de salida del país del niño, niña o adolescente, vinculando el juez su decisión directamente con el beneficio que la salida reporta al menor. Así, hemos seleccionado aquellas sentencias en que el interés superior es construido a partir del beneficio que genera para el niño, niña o adolescente estar rodeado de su familia extendida.

\section{Relevancia de los vínculos de familia para otorgar o rechazar la salida del país}

En la sentencia Rol n..$^{\circ}$ 42.642-2017, la Corte Suprema resuelve un recurso de casación en el fondo concede la autorización de salida del país solicitada por la madre. Entiende el máximo tribunal chileno que esta medida en nada afecta el interés superior de los hijos (dos en este caso), pues estos tienen una relación estable con el padre, que no se ve disminuida con la estadía de los niños en el extranjero, dado que la comunicación con el padre se puede realizar por medios telemáticos.

Para mayor ilustración, mencionamos mayores fundamentos de lo establecido por la Corte Suprema, adelantando que la nacionalidad de la madre y el país de destino serán factores de importancia en el proceso de reflexión judicial. En este sentido, se dejó constancia de que "el examen de la sentencia permite descartar, asimismo, que los razonamientos de los jueces del fondo elucubren en un plano abstracto, que desatiende el interés real de los niños -como alega el recurrente- por cuanto, en su fundamentación están presentes los fuertes lazos familiares que le dan estabilidad emocional y que aseguran que un viaje como el que se propone no alterará esos vínculos, está destacada la compañía de la madre, que tiene su cuidado personal y conoce sus necesidades, las evidentes habilidades sociales de I. y C. que permiten inferir serán potenciadas, la situación material que experimentará en Córdoba, al estar en un país al que se sienten pertenecer, rodeados de su familia y amigos

9 Rodríguez Pinto, M. S., "El cuidado personal de niños y adolescentes en la familia separada: criterios de resolución de conflictos de intereses entre padres e hijos en el nuevo derecho de familia chilena", Revista Chilena de Derecho, vol. 36, n. . 3, 2009, 545-586.

10 Lepin Molina, C., "Reforma a las relaciones paternos-filiales: análisis de la Ley n. . 20.680", Revista de Derecho. Escuela de Postgrado. Universidad de Chile, n. . 3, 2013, 285-308. 
cercanos, entre otros"11. Como podemos observar, en este caso se hace cargo el sentenciador del beneficio que la salida reportará a los niños, indicando que las habilidades sociales de los hijos serán potenciadas con esta salida del país.

A nuestro juicio, un criterio fundamental no declarado por el tribunal para otorgar la autorización fue que la madre tuviese la nacionalidad argentina. Súmese a lo anterior el hecho de que los niños nacieron en el nombrado país y, finalmente, también se estimó de relevancia la existencia de una red familiar materna en el país trasandino. Teniendo presente lo último, podríamos concluir que los vínculos de familia existentes en dicho país fueron ponderados y apreciados por la Corte Suprema, para efectos de conceder la autorización solicitada. En efecto, estimamos que con esta decisión el sentenciador otorga un reconocimiento a la familia extensa o extendida, esto es, a la familia que "se extiende más allá de dos generaciones y está basada en los vínculos de sangre de una gran cantidad de personas, incluyendo a los padres, niños, abuelos, tíos, tías, sobrinos, primos y demás"12, pues hace expresa mención de esta circunstancia en la sentencia.

Resulta de primer orden, siempre en el juicio en comento, la interpretación que realiza la Corte Suprema del principio del interés superior del niño, tomando en consideración que el padre manifiesta que se favorece el interés de la madre por sobre los hijos, al tener ésta una pareja en el país en que desea radicarse. Como podemos apreciar, lo planteado implica una cuestión de difícil apreciación y solución. A mayor detalle, se indicó lo siguiente: "El entendimiento del principio del interés superior debe ser acorde a la evolución social de las familias, lo que implica respetar las individualidades de quienes conforman el núcleo familiar y asumir que la exigencia de una figura ideal de madre que, en cuanto cuidadora de sus hijos, posterga su desarrollo en otras esferas de su vida responde a una concepción estereotipada y que tampoco favorece a los hijos que son objeto de tales cuidados" ${ }^{\prime 3}$.

Es importante considerar que los tiempos mandatan ir más allá del tradicional papel asignado a muchas mujeres, el que las reducía exclusivamente al rol de "madres encargadas del cuidado de sus hijos". A mayor detalle, toda mujer, con independencia del hecho de ser o no madre, tiene el derecho de perseguir su plena realización en otras áreas de la vida, sin que esto signifique el descuido del ejercicio del cuidado personal ${ }^{14}$. Es decir, a nuestro juicio la naturaleza de principio de interpretación del interés superior permite al sentenciador deducir que el mejor interés del niño, niña o adolescente no se ve afectado por la realización de la vida personal de la madre, y que en una sociedad como la actual, la noción de mujer dedicada absolutamente a la maternidad está superada.

11 Corte Suprema de Chile, 24 de abril de 2018, Rol n. ${ }^{\circ}$ 42.642-2017, considerando 4. . .

12 Martínez Vasallo, H., "La familia: una visión interdisciplinaria”, en Revista Médica Electrónica, vol. 37, n. . 5, 2015, 523-534.

13 Corte Suprema, Rol n. ${ }^{\circ}$ 42.642-2017, considerando 4. .

14 Similar sendero había recorrido la Corte Suprema en la sentencia Rol n. ${ }^{0}$ 73.900-2016. 
Para un escenario más acabado del caso que analizamos, debemos indicar que existe un voto disidente que considera quebrantado el principio de interés superior del niño con lo resuelto en la sentencia ${ }^{15}$.

Dentro de este criterio relativo a la familia extensa, resulta interesante, además, la sentencia Rol n. ${ }^{\circ}$ 11.966-2018, resolución que fundamenta el beneficio desde esta perspectiva, indicando expresamente lo siguiente: "[...] en consecuencia, se debe concluir que al haber rechazado la salida del país para radicarse junto a su madre y a sus hermanos en España, se ha cometido una infracción de derecho que debe remediarse, puesto que no se reconoce el beneficio cierto para la niña de poder contar durante su desarrollo con la presencia de sus hermanos, lo que constituye una condición insoslayable conforme el artículo 49 de la Ley n. ${ }^{\circ}$ 16.618, la que se ha visto vulnerada, teniendo en consideración el principio del interés superior del niño previsto en el artículo 242 del Código Civil, el artículo 16 de la Ley n. ${ }^{\circ} 19.968$ y en el artículo 3 n. ${ }^{\circ} 1$ de la Convención sobre los derechos del Niño"16. Una mirada como ésta es conteste con el artículo $5 .^{\circ}$ de la Convención Internacional sobre los Derechos del Niño, texto que consagra como obligación de los estados parte respetar las responsabilidades y los derechos de los padres y madres, así como de la familia ampliada, en el sentido de impartir al niño una orientación apropiada a la evolución de sus capacidades, destacando de esta forma el rol del referido tipo de estructura familiar. En virtud de lo señalado, destacamos el hecho de que la individualizada sentencia reconoce que es beneficioso para el niño, niña o adolescente crecer en compañía de su madre y hermanos, esto es, se ha considerado la relevancia del derecho a la unidad familiar.

En un caso similar, la Corte Suprema también tuvo en cuenta, entre otros factores, los vínculos familiares existentes en otro país. Este juicio fue decidido en primera instancia por el Tribunal de Familia de Calama y la sentencia fue objeto de recurso de casación en el fondo ante la Corte Suprema. El máximo tribunal de Chile mencionó expresamente la relevancia de la presencia de familia extensa en el país respecto del cual se solicita la autorización de salida.

En palabras de la Corte Suprema, "la sentencia impugnada tuvo en consideración que el niño tiene como figuras predominantes a su madre y abuela materna, con quienes vive actualmente y se trasladarían con él a Salta; que, si bien tiene una buena relación con su padre, no es de una significación comparable a la que tiene con su madre y abuela, y que la demandante tiene familia extendida en esa ciudad, de manera que el traslado del niño no le generará desarraigo. Asimismo, tuvo también presente que el niño tendrá acceso a educación y salud en Argentina. Por estas

15 En la consideración n. ${ }^{\circ} 9$ el ministro Blanco, disidente, indica: "Que en este contexto, la autorización de salida del país en estudio, quebranta de manera evidente el interés superior de I. y C., pues la vida junto a la actual pareja y a la familia extendida de su madre no constituye, a juicio de este disidente, un factor que atendida su actual etapa de desarrollo, sea más trascendente que su derecho a mantener un vínculo afectivo con su padre, a quien reconocen e identifican como parte de su familia".

Corte Suprema de Chile, 14 de febrero de 2019, Rol n. ${ }^{\circ}$ 11966-2018, considerando 6.. 
consideraciones, estimó que la salida del niño cumple con el estándar exigido por el interés superior del niño"17.

En este juicio, además, el máximo tribunal chileno se refiere al interés de la madre, señalando en dicho sentido lo siguiente: "La sentencia no ve que el traslado a dicha ciudad vaya a perjudicar al niño. La obligación de considerar su interés superior no significa que ante la falta de garantía de que el niño estará mejor en Salta de lo que está actualmente en Calama justifique sacrificar el interés de la demandante y su madre. En la medida en que la resolución recurrida ha considerado el interés superior del niño, no ha incurrido en infracción de ley que justifique su casación"18. Se hace presente en la sentencia que analizamos que se podría mantener una relación directa y regular con el padre por medios tecnológicos, más un régimen de vacaciones y pernoctación que fija la misma sentencia. Es decir, podemos ir vislumbrando que para los tribunales chilenos el ejercicio de la relación directa y regular no se circunscribe exclusivamente a la comunicación física-directa entre padre, madre e hijos, sino que bien puede comprender otras formas diversas de relación. En concordancia con lo anterior, sabido es que las nuevas formas de comunicación que nos ofrece el actual estado de desarrollo de la tecnología permiten una mayor calidad e interacción que benefician a los que acuden a ellas.

Siguiendo este mismo criterio, encontramos la sentencia dictada por la Corte de Apelaciones de Valparaíso. Así, se ha revocado la denegación de autorización para salir del país hacia Alemania de la niña $\mathrm{D}$, quien tiene familia extensa en dicho país. Indica el mencionado tribunal " [...] que, en las anotadas condiciones, imbuido en el principio del interés superior de la niña, resulta conveniente autorizar la salida del país de la menor D, para reunirse con sus familiares sanguíneos en Alemania, integrarse a la misma y desarrollarse a plenitud"19.

Bajo el mismo criterio en análisis podemos clasificar a la sentencia de la Corte Suprema que rechaza el recurso de casación intentado en la causa Rol n..$^{\circ} 41.030$ 2016 que confirma la sentencia que autoriza la salida a China por tres años del niño $\mathrm{Z}$, cuyos padres son de origen chino, y que actualmente tiene seis años, pero desde su nacimiento y hasta los cuatro años vivió con sus abuelos maternos en China. La Corte resuelve nuevamente teniendo presente que existe familia extensa en el país respecto del cual se autoriza la salida. En este sentido, considera el nombrado tribunal que el beneficio que exige la ley $n .^{\circ} 16.618$ se manifiesta de la siguiente manera: "Los jueces se han preocupado de la colisión de derechos[,] y el artículo 49 de la ley de menores establece, específicamente, que el traslado debe ser justificado con un beneficio para el niño; pues, en este caso, se está preservando la identidad del niño en el país que lo acogió los primeros años de vida, y el cual siente como suyo, su etnia es oriental, su idioma es el chino, su madre y todos sus abuelos viven en China, por

17 Corte Suprema de Chile, $1 .^{\circ}$ de marzo de 2018, Rol n..$^{\circ}$ 37.937-2017, considerando 5.. .

18 Corte Suprema, Rol n. ${ }^{\circ} 37.937-2017$, considerando 6. ${ }^{\circ}$.

19 Corte de Apelaciones de Valparaíso, 3 de agosto de 2012, Rol n. ${ }^{\circ} 382-2012$, considerando 4. ${ }^{\circ}$. 
lo cual no se puede sostener que los jueces del fondo no se han preocupado del interés superior de $\mathrm{Z}$, ya que íntimamente ligado a éste se encuentra el poder mantener la identidad del niño, lo cual se logra con el fallo"20.

Resulta novedoso el hecho de que el sentenciador pondera como un elemento para configurar el beneficio de la salida del niño la preservación de la identidad, derecho recogido en la Convención sobre los Derechos del Niño, específicamente en el artículo $8 .^{\circ}$, numeral 1. Este derecho es entendido como "el conjunto de atributos y características que permiten individualizar a la persona en sociedad. Identidad personal es todo aquello que hace que cada cual sea 'uno mismo' y no 'otro""21. Es interesante la mención hecha por el tribunal a este derecho, pues no ha sido desarrollado en las otras resoluciones objeto de este estudio. En esta senda, razonó el sentenciador que reconocer el derecho a la identidad del niño supone la exigencia del respeto de la propia biografía, con sus luces y sus sombras, con lo que exalta y con lo que degrada 22 .

En la sentencia dictada por la Corte Suprema en la causa Rol n. ${ }^{\circ}$ 30.395-2015, para la resolución del asunto controvertido se toma en consideración, a nuestro parecer, la circunstancia de que la madre, quien tiene el cuidado personal, es de nacionalidad mexicana y tiene red de apoyo en su país de origen. En estos términos, el mencionado tribunal indica "[...] que respecto de la falta que se esgrime en relación al Interés Superior del Niño, cabe señalar que este principio no parece preterido por la decisión de los sentenciadores, al resolver del modo que lo han hecho, pues de acuerdo a los antecedentes y presupuestos que han considerado y establecido, la determinación se ajusta a lo que aparece como beneficioso también para el niño y no sólo cede en favor de los intereses de su madre, en cuanto posibilita que el mismo se reencuentre con su familia, país y cultura de origen -por línea materna-; además, se ha establecido un régimen comunicacional para que mantenga una vinculación con su padre, lo que no ha sido desconocido o suprimido" 23 .

Resulta interesante constatar que la Corte Suprema estima como beneficio derivado de la salida la reunificación o el reencuentro familiar, entendidos como el "derecho que asiste a los extranjeros residentes de un determinado Estado a solicitar la entrada y residencia de algunos miembros de su familia" 24 . Con lo anterior, nos

20 Corte Suprema, 5 de enero de 2017, Rol n..$^{\circ}$ 41.030-2016, considerando 5. .

21 Lovera Parmo, D. y Gauche Marchetti, X., "Identidad de género de niños, niñas y adolescentes: una cuestión de derechos", Ius et Praxis, vol. 7, n. ' 2, 2019, 359-402.

22 Corral Talciani, H., "Intereses y derechos en colisión sobre la identidad del progenitor biológico: los supuestos de la madre soltera y del donante de gametos", Ius et Praxis, vol. 16, n. . 2, 2010, 57-87.

23 Corte Suprema, 20 de abril de 2016, Rol 30.390-2015, considerando 6. .

24 Araya Rojas, C. y Garay TAPIA, D., "El derecho a la reagrupación familiar del extranjero en Chile. Realidad y desafíos", memoria para optar al grado de licenciado en Ciencias Jurídicas, 2018, 36, disponible en [http://repositorio.uchile.cl/bitstream/handle/2250/150684/El-derecho-a-la-reagrupaci\% C3\%B3n-familiar-del-extranjero-en-Chile-realidad-y-desaf\%C3\%ADos.pdf?sequence=1\&isAllow ed=y] [consultado el 20 de septiembre de 2019]. 
parece que el tribunal reconoce una realidad impuesta por la evolución de los flujos migratorios regulada especialmente en el ámbito del derecho internacional. En efecto, como lo ha indicado Mondaca, "a nivel internacional en numerosos instrumentos se ha disciplinado el derecho a la reunificación familiar, y ha sido regulado con mayor detalle en el continente europeo" 25 .

No podemos soslayar la referencia que la sentencia realiza al interés de la madre. En este sentido, afirmamos que dicho interés no debe entenderse como necesariamente contrapuesto al interés superior del niño, niña o adolescente; es más, creemos que tales intereses pueden complementarse, sin desconocer que la propia noción del interés superior del niño exige que el beneficio que primeramente debe buscarse es el del niño, niña o adolescente, no el de los padres. Por tanto, mal podría entenderse que existe una colisión entre ambos intereses, si cualquier otro queda subordinado al nombrado principio, pues el "derecho de prioridad del interés superior del niño/niña prima sobre cualquier otro que pueda afectar derechos fundamentales del niño/niña. Así, ni el interés de los padres, ni el de la sociedad, ni el del Estado pueden ser considerados prioritarios en relación con los derechos del niño/niña" ${ }^{26}$. Por lo tanto, "cuando hay menores de edad involucrados, el eje de la contienda debe virar a los fines de decidir lo que responda a su interés superior, así como aquello que mejor proteja sus intereses y esperar que ello se compatibilice con el interés familiar"27.

Es de importancia resaltar que, en un sentido negativo, la ausencia de una familia extendida ha resultado ser un factor decisorio litis. A contrario sensu, en algunos juicios, comprobando el tribunal la inexistencia de familia extensa en el país de destino, no se ha concedido la autorización. Así, la Corte de Apelaciones de Santiago revocó la decisión del Tercer Juzgado de Familia de Santiago que concede la autorización para salir del país y, como consecuencia de ello, impide que se radique un niño en Alemania con su madre, de nacionalidad rusa. En concepto de la mencionada Corte, el hijo en común no tiene mayor vinculación con Alemania, pues ha estado desde los seis meses de vida en Chile. A mayor detalle, en palabras de la Corte de Apelaciones de Santiago, "[...] sin perjuicio de lo que se viene diciendo, tampoco resulta, Alemania, el país de origen del niño, como el lugar donde radica el centro social de vida del niño, es decir el lugar donde radican sus vínculos afectivos derivados de su vida cotidiana; pues su padre con el que comparte el mismo origen alemán reside en Chile, ya que su madre es rusa y no existen antecedentes en Alemania de que mantenga una red de apoyo familiar. En ese orden de ideas, se logró acreditar

25 Para mayor profundidad en este contenido, véase Mondaca Miranda, A., "El derecho a la reunificación familiar. Análisis desde el derecho chileno", en Del Carpio RodríGuez, C. (coord.), Derecho de familia y personas: familia, mujer, niñez y violencia, Editorial Universitaria San Agustín de Arequipa, Arequipa, 2019, 41.

26 Aguilar Cavallo, G., "El principio del interés superior del niño y la Corte Interamericana de Derechos Humanos", Revista de Estudios Constitucionales, vol. 6, n. ${ }^{\circ}$ 1, 2008, 223-247.

27 Daziano, A., "El interés superior de los hijos en contraposición al interés de sus representantes", Revista de Derecho de Familia, vol. 5, 2019, 289-296. 
en el proceso, no sólo que el niño ha permanecido la mayor parte de su corta vida en Chile, seis años, de los tres meses de edad que tenía al momento de llegar a Chile, sino que él ya se encuentra inserto en Chile, además está asistiendo a un centro educacional en el que está desarrollando vínculos afectivos y sociales, que permiten determinar que el lugar de su residencia habitual es Chile y no Alemania"28.

\section{Conclusiones}

Podemos concluir que resulta un hecho decisivo para la Corte Suprema y las cortes de apelaciones de Chile, llegado el momento de confirmar o rechazar la salida al extranjero de un niño, niña o adolescente, la existencia de familia extensa en el país respecto del cual se solicita la autorización. Además, podemos concluir que el estudio de estos fallos nos permite afirmar que progresivamente los tribunales de justicia están reconociendo la importancia de la familia extendida, no solo como forma de organización social, sino en la vida de los niños, niñas o adolescentes.

Finalmente, podemos concluir que existen votos disidentes en las sentencias analizadas que reflexionan acerca de que las oportunidades de la madre en el extranjero serían contrarias al interés superior de los niños, niñas o adolescentes. Creemos que dicho razonamiento resulta anacrónico, atendiendo a la necesaria superación del papel históricamente asignado a la mujer, el que la ha circunscrito a la labor del cuidado de los hijos.

\section{Referencias}

Aguilar Cavallo, G., "El principio del interés superior del niño y la Corte Interamericana de Derechos Humanos", Revista de Estudios Constitucionales, vol. 6, . $^{\circ} 1,2008$.

Corral Talciani, H., "Intereses y derechos en colisión sobre la identidad del progenitor biológico: los supuestos de la madre soltera y del donante de gametos", Ius et Praxis, vol. 16, n. ${ }^{\circ}$ 2, 2010.

Daziano, A., "El interés superior de los hijos en contraposición al interés de sus representantes", Revista de Derecho de Familia, vol. 5, 2019.

Lepin Molina, C., "Reforma a las relaciones paterno-filiales. Análisis de la Ley n. ${ }^{\circ}$ 20.680", Revista de Derecho Universidad de Chile, n. . 3, 2013.

Lovera Parmo, D. y Gauche Marchetti, X., "Identidad de género de niños, niñas y adolescentes: una cuestión de derechos", Ius et Praxis, vol. 7, n. ${ }^{\circ}$ 2, 2019. 
Martínez Vasallo, H., "La familia: una visión interdisciplinaria”, Revista Médica Electrónica, vol. 37, n. ${ }^{\circ}$ 5, 2015, 523-534.

Mondaca Miranda, A., "El derecho a la reunificación familiar. Análisis desde el derecho chileno", en Del Carpio Rodríguez, C. (coord.), Derecho de familia y personas: familia, mujer, niñez y violencia, Editorial Universitaria San Agustín de Arequipa, Arequipa, 2019.

Montecinos Tota, A., "Interés superior del niño como fundamento de la autorización de su salida definitiva al extranjero", en Domínguez Hidalgo, C. (coord.). Estudios de Derecho de Familia III. Terceras Jornadas Nacionales. Facultad de Derecho. Pontificia Universidad Católica de Chile, Santiago, Thomson Reuters, 2018.

Orellana Torres, F., Manual de Derecho Procesal, 3. a ed., Santiago, Librotecnia, 2010.

Ramos Pazos, R. Derecho de Familia, tomo II, 7. ed., Santiago, Editorial Jurídica de Chile, 2017.

Rodríguez Pinto, M. S., "El cuidado personal de niños y adolescentes en la familia separada: criterios de resolución de conflictos de intereses entre padres e hijos en el nuevo derecho de familia chilena", Revista Chilena de Derecho, vol. 36, n. 3,2009 .

Romero Seguel, A., Aguirrezábal Grünstein, M. y Baraona González, J., "Revisión crítica de la causal fundante del recurso de casación en el fondo en materia civil", Ius et Praxis, año 14, n. ${ }^{\circ}$ 1, 2008. 